\title{
Prevalence of depression among patients with multiple sclerosis in
} Erbil city

\section{Abstract}

Background and objective: Multiple sclerosis is one of the chronic central nervous system diseases. Depression comorbidity is common with multiple sclerosis. This study aimed to determine the prevalence of depression among patients with multiple sclerosis and the relation of patient demographic data and disease status.

Methods: A cross-sectional study was conducted in Rizgary Teaching Hospital in Erbil City, in a one-year duration from October 2017 to October 2018. The sample size was 169 known patients with multiple sclerosis, which was collected randomly. Beck Depression Inventory was used. The statistical package for the social sciences (version 25) was used for data analysis. Pearson Chi-square and Fisher's Exact Test were used to finding the association between various variables and depression.

Results: The prevalence of depression among patients with multiple sclerosis was $53.5 \%$. Age group more than 50 years was found more depressed $(66.7 \%, P=0.006)$. Depression is more with those with multiple sclerosis for 10 years and more $(84.6 \%)$ with a statistically significant association $(P=0.021)$. Treatment by rituximab show more depression $(85.7 \%, P=0.039)$. The frequency of severity of major depressive disorder was (mild $31.8 \%$, moderate $52.9 \%$, and severe $15.3 \%$ ) and showed no significant association with different variables.

Conclusion: The prevalence of depression among patients with multiple sclerosis was high. The age group of more than 50 years, duration of multiple sclerosis equal or more than 10 years, and rituximab treatment were regarded as risk factors.

Keywords: Depression; Patients with multiple sclerosis; Erbil city.

\section{Introduction}

Multiple sclerosis (MS) is one of the central nervous system (CNS) diseases, which is chronic, inflammatory, and immune-mediated, typically presents in the third or fourth decade of life. ${ }^{1,2}$ It is one of the most frequent nontraumatic disabling neurologic diseases, which affects 12,000 people in the United States alone per year. ${ }^{3}$ There is high variability in the disease course. Its outcome is hard to predict, with no known cure. ${ }^{4}$ Patients may be grouped into four categories; Relapsing-remitting (RR) MS, Secondary progressive (SP) MS, Primary progressive (PP) MS, and Progressive-relapsing (PR) MS, based on the course of the disease. ${ }^{5}$ Nearly $87 \%$ of patients are of RRMS type, characterized by acute attacks (relapses) followed by partial or full recovery (remission). There are a heterogeneous group of symptoms, including changes in vision (unilateral visual loss, diplopia), weakness, incoordination, sensory loss or distortions, or changes in bowel and bladder function, cognitive change, fatigue, and mood disturbance. ${ }^{6}$ Multifocal involvement of white and gray matter in the central nervous system can cause physical impairment and disability, with cognitive and psychological changes that often lessen patients' quality of life, occupational competence, and social interactions. ${ }^{7}$ Psychiatric comorbidity is common in

${ }^{1}$ Department of Psychiatry, College of Medicine, Hawler Medical University, Erbil, Iraq.

* Correspondence: warjin.yasin@yahoo.com 
patients with $\mathrm{MS}^{8}{ }^{8}$ This comorbidity is associated with lower quality of life, more fatigue, and reduced adherence to treatment of $\mathrm{MS}^{9}$ Among psychiatric manifestations, depression is the most common one. ${ }^{10}$ In the nineteenth century, Charcot gave the first detailed description of multiple sclerosis in his lectures. The psychiatric symptoms such as pathological laughing and weeping, euphoria, mania, hallucinations, and depression were noted by Charcot. $^{11}$ The reason behind the excess of depression seen in persons with MSis suggested as a direct or indirect association between MS-related neurobiological factors including altered immune function, CNS lesions, and abnormalities in hypothalamic functioning. ${ }^{12}$ Depression affects hundreds of millions of people all over the world. It can occur at any age from childhood to late life and is a potentially life-threatening disorder that causes severe distress and disruption of life and, if left untreated, can be fatal. ${ }^{13}$ The depression in multiple sclerosis is adjustable to treatment both with psychotherapy as well as with pharmacotherapy, which may not only relieve current suffering and dysfunction but may also improve the long-term prognosis for the depression and even multiple sclerosis. ${ }^{14}$ At the time of exacerbation, there is an increased rate of depression and suicide, as shown by several studies, and clinical evidence of an association between immune activation and depression. ${ }^{15}$ In interaction with time, coping capacity, reduced social/lifestyle activities, and psychological impact of MS on health are independent predictors for the occurrence of depressive symptoms in MS. ${ }^{16}$ Drugs used in the treatment of MS also has some rule in producing depression and other psychiatric morbidities. ${ }^{17}$ This study aimed to determine the prevalence of depression among patients with multiple sclerosis and its types and the relation of patient demographic data and disease status. Also, to determine the relationship of sociodemographic data with type and severity of depression.

\section{Methods}

A cross-sectional study was conducted at Rizgary Teaching Hospital in Erbil City, in a one-year duration from October 2017 to October 2018. The study included patients diagnosed and attending multiple sclerosis committee at Rizgary Teaching Hospital during the data collection time. A sample of 169 known patients with multiple sclerosis out of 300 patients was selected. In terms of the numbers that have been selected above which is 169 are resulted by the following calculation: $x=Z(c / 100) 2 r(100-r)$, $\mathrm{n}=\mathrm{N} x /((\mathrm{N}-1) \mathrm{E} 2+\mathrm{x}), \mathrm{E}=$ Sqrt $[(\mathrm{N}-\mathrm{n}) \mathrm{x} / \mathrm{n}$ $(\mathrm{N}-1)]$. Population size in the above calculation is represented as $\mathrm{N}$. The fraction of responses that the researcher is interested in represented as $r, Z(c / 100)$ represented as a serious value for the confidence level, which is $c$, and $\mathrm{E}$ as the margin of error. The recommended sample size which is measured by using the above mentioned calculator, the maximum acceptable error of $5 \%$, desired confidence level of $95 \%$, and response distribution of $50 \% .^{18}$ However 169 patients had been selected through stratified random sampling in which the first four patients from each seven had been selected by using the files of patients in the committee. Out of 169 patients, 10 patients had been excluded from the study because they suffered from other medical illnesses in addition to multiple sclerosis. Out of the remaining patients who are 159 , their ages are between 18 to 65 years. Both genders of males and females were included. Sociodemographic characteristics had been obtained by a special questionnaire form for all patients who were attending the study. The independent variables evaluated to explain depression were socio -demographics (age, gender, marital status, educational background, and socioeconomic status) and characteristics of the disease (types, duration, and types of medication). The socioeconomic status of the participant was determined through 
the number of family members, the number of rooms, the number of years of formal education of both father and mother, possession of a car, monthly income, and type of housing e.g., owned, rented, helped, or partially owned, this system borrowed with modifications from other studies. ${ }^{19}$ The study was approved by the Ethics Committee and Scientific Research Units in Kurdistan Board for Medical Specialties. Informed consent had been taken from the hospital intended to do the research in addition to the concerned committee. All interviews were administered face-to-face. Verbal consent was taken from the patient before participation after clarification of the aim, procedure, and ability to withdraw at any stage the patient wanted After randomization, each patient was assessed by Beck Depression Inventory. Beck Depression Inventory scale takes 5-10 minutes to administer, is a 21-item instrument for assessing the existence and severity of symptoms of depression among the psychiatric patients as well as possible depression in the normal population. This inventory is rated on a four-point scale ranging from 0 (no symptom) to 3 (severe symptom) ${ }^{20}$ All demographic data and questionnaire results were registered in a special inventory and analyzed using the statistical package for the social sciences (version 25). Chi-square test statistic $\left(x^{2}\right)$ to find the significance of the association between various variables and depression was used. When the expected count of more than $20 \%$ of the cells of the tables was less than 5, Fisher's Exact Test was used. When the $P$ value was $<0.05$ it was considered statistically significant.

\section{Results}

The age ranged from 18 to 65 years (mean $\pm \mathrm{SD}=36.28 \pm 9.794$ years). The total number of males was 54, and females was 105.Furthermore, 43 of them were single, 115 married, and one widow. About educational background, four were illiterate, 11 only read and write,
28 primary school, 48 intermediate and secondary school, and 68 high education. According to socioeconomic status, 62, 72 , and 25 had lower, moderate, and higher socioeconomic status respectively, as shown in Table 1. Most of the patients were of relapsing remitting type of multiple sclerosis about 151. Moreover, 146 of them had multiple sclerosis in a duration of less than 10 years. One hundred thirteen patients received beta interferon treatment, as shown in Table 2. Among 159 patients with multiple sclerosis, $85(53.5 \%)$ of them are suffering from a major depressive disorder. Depression was found more among the age group (more than 50 years) with $(66.7 \%$ with $P=0.006)$, as shown in Table 1. The difference was statistically significant with the duration of MS since depression was more with those suffering from MS for 10 years and more than those suffering from MS for less than 10 years $(84.6 \%$ vs $50.7 \%$ with $P=0.021)$. Depression was more frequent among those who used rituximab as a treatment of MS than those used other medications (85.7\% with $P=0.039)$, as shown in Table 2. 
Prevalence of depression among patients with ......

Zanco J. Med. Sci., Vol. 24, No. (2), August, 2020 https://doi.org/10.15218/zjms.2020.029

Table 1: Association of certain sociodemographic characteristics with depression in patients with multiple sclerosis.

\begin{tabular}{|c|c|c|c|c|c|c|c|}
\hline \multirow[t]{2}{*}{ Variables } & \multicolumn{2}{|c|}{ Depression } & \multicolumn{2}{|c|}{ No depression } & \multicolumn{2}{|c|}{ Total } & \multirow[t]{2}{*}{$P$ value } \\
\hline & No. & $\%$ & No. & $\%$ & No. & $\%$ & \\
\hline \multicolumn{8}{|l|}{ Age } \\
\hline $18-28$ & 11 & 28.9 & 27 & 71.1 & 38 & 100 & \\
\hline $29-39$ & 37 & 61.7 & 23 & 38.3 & 60 & 100 & \\
\hline $40-50$ & 31 & 59.6 & 21 & 40.4 & 52 & 100 & $0.006^{\star *}$ \\
\hline more than 50 & 6 & 66.7 & 3 & 33.3 & 9 & 100 & \\
\hline \multicolumn{8}{|l|}{ Gender } \\
\hline Male & 24 & 44.4 & 30 & 55.6 & 54 & 100 & $0.131^{*}$ \\
\hline Female & 61 & 58.1 & 44 & 41.9 & 105 & 100 & \\
\hline \multicolumn{8}{|l|}{ Marital status } \\
\hline Single & 18 & 41.9 & 25 & 58.1 & 43 & 100 & \\
\hline Married & 66 & 57.4 & 49 & 42.6 & 115 & 100 & $0.107^{\star *}$ \\
\hline Widow & 1 & 100.0 & 0 & 0.00 & 1 & 100 & \\
\hline \multicolumn{8}{|l|}{ Educational background } \\
\hline Illiterate & 4 & 100.0 & 0 & 0.00 & 4 & 100 & \\
\hline Read and write & 6 & 54.5 & 5 & 45.5 & 11 & 100 & \\
\hline Primary school & 17 & 60.7 & 11 & 39.3 & 28 & 100 & $0.349^{* *}$ \\
\hline Intermediate and secondary & 25 & 52.1 & 23 & 47.9 & 48 & 100 & \\
\hline $\begin{array}{l}\text { Diploma, university and high } \\
\text { education }\end{array}$ & 33 & 48.5 & 35 & 51.5 & 68 & 100 & \\
\hline \multicolumn{8}{|l|}{ Socioeconomic status } \\
\hline Lower & 37 & 59.7 & 25 & 40.3 & 62 & 100 & \\
\hline Moderate & 39 & 54.2 & 33 & 45.8 & 72 & 100 & $0.137^{*}$ \\
\hline High & 9 & 36.0 & 16 & 64.0 & 25 & 100 & \\
\hline Total & 85 & 53.5 & 74 & 46.5 & 159 & 100 & \\
\hline
\end{tabular}

${ }^{*}$ Chi-square test

** Fisher's exact test 
Prevalence of depression among patients with .......

Zanco J. Med. Sci., Vol. 24, No. (2), August, 2020 https://doi.org/10.15218/zjms.2020.029

Table 2: Association of types, duration, and medication used in multiple sclerosis with depression.

\begin{tabular}{|c|c|c|c|c|c|c|c|}
\hline \multirow[t]{2}{*}{ Variables } & \multicolumn{2}{|c|}{ Depression } & \multicolumn{2}{|c|}{ No depression } & \multicolumn{2}{|c|}{ Total } & \multirow[t]{2}{*}{$P$ value } \\
\hline & No. & $\%$ & No. & $\%$ & No. & $\%$ & \\
\hline \multicolumn{8}{|l|}{ Types of Multiple sclerosis } \\
\hline $\begin{array}{l}\text { Relapsing-remitting multiple } \\
\text { sclerosis }\end{array}$ & 79 & 52.3 & 72 & 47.7 & 151 & 100 & \\
\hline $\begin{array}{l}\text { Secondary progressive multiple } \\
\text { sclerosis }\end{array}$ & 2 & 66.7 & 1 & 33.3 & 3 & 100 & $0.461^{*}$ \\
\hline $\begin{array}{l}\text { Primary progressive multiple } \\
\text { sclerosis }\end{array}$ & 1 & 50.0 & 1 & 50.0 & 2 & 100 & \\
\hline $\begin{array}{l}\text { Progressive-relapsing multiple } \\
\text { sclerosis }\end{array}$ & 3 & 100.0 & 0 & 0.00 & 3 & 100 & \\
\hline \multicolumn{8}{|l|}{ Duration of Multiple sclerosis } \\
\hline Less than 10 years & 74 & 50.7 & 72 & 49.3 & 146 & 100 & $0.021^{*}$ \\
\hline Equal or more than 10 years & 11 & 84.6 & 2 & 15.4 & 13 & 100 & \\
\hline \multicolumn{8}{|l|}{ Types of medication } \\
\hline Beta interferon & 51 & 45.1 & 62 & 54.9 & 113 & 100 & \\
\hline Fingolimod & 13 & 68.4 & 6 & 31.6 & 19 & 100 & \\
\hline Tysabri & 5 & 71.4 & 2 & 28.6 & 7 & 100 & $0.039^{* *}$ \\
\hline Rituximab & 6 & 85.7 & 1 & 14.3 & 7 & 100 & \\
\hline Mitoxantron & 5 & 71.4 & 2 & 28.6 & 7 & 100 & \\
\hline Without treatment & 5 & 83.3 & 1 & 16.7 & 6 & 100 & \\
\hline Total & 85 & 53.5 & 74 & 46.5 & 159 & 100 & \\
\hline
\end{tabular}

${ }^{*}$ Chi-square test

${ }^{* *}$ Fisher's exact test 
The frequency of severity of the major There was no significant association of depressive disorder (MDD) was $31.8 \%$ for the mild type, $52.9 \%$ for the moderate type, severity of depression with different and $15.3 \%$ for the severe type (Figure 1 ). variables, as shown in Tables 3 and 4.

Table 3: Association of certain sociodemographic characteristics with the severity of depression in patients with multiple sclerosis.

\begin{tabular}{|c|c|c|c|c|c|c|c|}
\hline \multirow{3}{*}{ Variables } & \multicolumn{6}{|c|}{ Depression } & \multirow{3}{*}{$P$ value } \\
\hline & \multicolumn{2}{|c|}{ Mild } & \multicolumn{2}{|c|}{ Moderate } & \multicolumn{2}{|c|}{ Severe } & \\
\hline & No. & $\%$ & No. & $\%$ & No. & $\%$ & \\
\hline \multicolumn{8}{|l|}{ Age } \\
\hline $18-28$ & 3 & 27.3 & 7 & 63.6 & 1 & 9.1 & \\
\hline $29-39$ & 10 & 27.0 & 22 & 59.5 & 5 & 13.5 & \\
\hline $40-50$ & 11 & 35.5 & 14 & 45.2 & 6 & 19.4 & $0.790^{\star *}$ \\
\hline More than 50 & 3 & 50.0 & 2 & 33.3 & 1 & 16.7 & \\
\hline \multicolumn{8}{|l|}{ Gender } \\
\hline Male & 8 & 33.3 & 9 & 37.5 & 7 & 29.2 & $0.057^{*}$ \\
\hline Female & 19 & 31.1 & 36 & 59.0 & 6 & 9.8 & \\
\hline \multicolumn{8}{|l|}{ Marital status } \\
\hline Single & 7 & 38.9 & 10 & 55.6 & 1 & 5.6 & $0.408^{* \star}$ \\
\hline Married & 19 & 28.8 & 35 & 53.0 & 12 & 18.2 & \\
\hline Widow & 1 & 100.0 & 0 & 0.00 & 0 & 0.00 & \\
\hline \multicolumn{8}{|l|}{ Educational background } \\
\hline Illiterate & 1 & 25.0 & 2 & 50.0 & 1 & 25.0 & \\
\hline Read and write & 1 & 16.7 & 4 & 66.7 & 1 & 16.7 & \\
\hline Primary school & 5 & 29.4 & 9 & 52.9 & 3 & 17.6 & $0.276^{* *}$ \\
\hline Intermediate and secondary & 7 & 28.0 & 11 & 44.0 & 7 & 28.0 & \\
\hline $\begin{array}{l}\text { Diploma, university and } \\
\text { high education }\end{array}$ & 13 & 39.4 & 19 & 57.6 & 1 & 3.0 & \\
\hline \multicolumn{8}{|l|}{ Socioeconomic status } \\
\hline Lower & 9 & 24.3 & 21 & 56.8 & 7 & 18.9 & $0.442^{* *}$ \\
\hline Moderate & 14 & 35.9 & 21 & 53.8 & 4 & 10.3 & \\
\hline High & 4 & 44.4 & 3 & 33.3 & 2 & 22.2 & \\
\hline Total & 27 & 31.8 & 45 & 52.9 & 13 & 15.3 & \\
\hline $\begin{array}{l}{ }^{*} \text { Chi-square test } \\
{ }^{* *} \text { Fisher's exact test }\end{array}$ & & & & & & & \\
\hline
\end{tabular}


Table 4: Association of types, duration, and medication used in multiple sclerosis with severity of depression.

\begin{tabular}{|c|c|c|c|c|c|c|c|}
\hline \multirow{3}{*}{ Variables } & \multicolumn{6}{|c|}{ Depression } & \multirow{3}{*}{$P$ value } \\
\hline & \multicolumn{2}{|c|}{ Mild } & \multicolumn{2}{|c|}{ Moderate } & \multicolumn{2}{|c|}{ Severe } & \\
\hline & No. & $\%$ & No. & $\%$ & No. & $\%$ & \\
\hline \multicolumn{8}{|l|}{ Types of Multiple sclerosis } \\
\hline $\begin{array}{l}\text { Relapsing-remitting multiple } \\
\text { sclerosis }\end{array}$ & 25 & 31.6 & 42 & 53.2 & 12 & 15.2 & \\
\hline $\begin{array}{l}\text { Secondary progressive multiple } \\
\text { sclerosis }\end{array}$ & 1 & 50.0 & 1 & 50.0 & 0 & 0.00 & $0.914^{* *}$ \\
\hline $\begin{array}{l}\text { Primary progressive multiple } \\
\text { sclerosis }\end{array}$ & 0 & 0.00 & 1 & 100.0 & 0 & 0.00 & \\
\hline $\begin{array}{l}\text { Progressive-relapsing multiple } \\
\text { sclerosis }\end{array}$ & 1 & 33.3 & 1 & 33.3 & 1 & 33.3 & \\
\hline \multicolumn{8}{|l|}{ Duration of Multiple sclerosis } \\
\hline Less than 10 years & 25 & 33.8 & 39 & 52.7 & 10 & 13.5 & $0.410^{* *}$ \\
\hline Equal or more than 10 years & 2 & 18.2 & 6 & 54.5 & 3 & 27.3 & \\
\hline \multicolumn{8}{|l|}{ Types of medication } \\
\hline Beta interferon & 16 & 31.4 & 25 & 49.0 & 10 & 19.6 & \\
\hline Fingolimod & 6 & 46.2 & 6 & 46.2 & 1 & 7.7 & \\
\hline Tysabri & 1 & 20.0 & 4 & 80.0 & 0 & 0.00 & $0.925^{\star *}$ \\
\hline Rituximab & 2 & 33.3 & 3 & 50.0 & 1 & 16.7 & \\
\hline Mitoxantron & 1 & 20.0 & 3 & 60.0 & 1 & 20.0 & \\
\hline Without treatment & 1 & 20.0 & 4 & 80.0 & 0 & 0.00 & \\
\hline Total & 27 & 31.8 & 45 & 52.9 & 13 & 15.3 & \\
\hline
\end{tabular}

${ }^{* *}$ Fisher's exact test

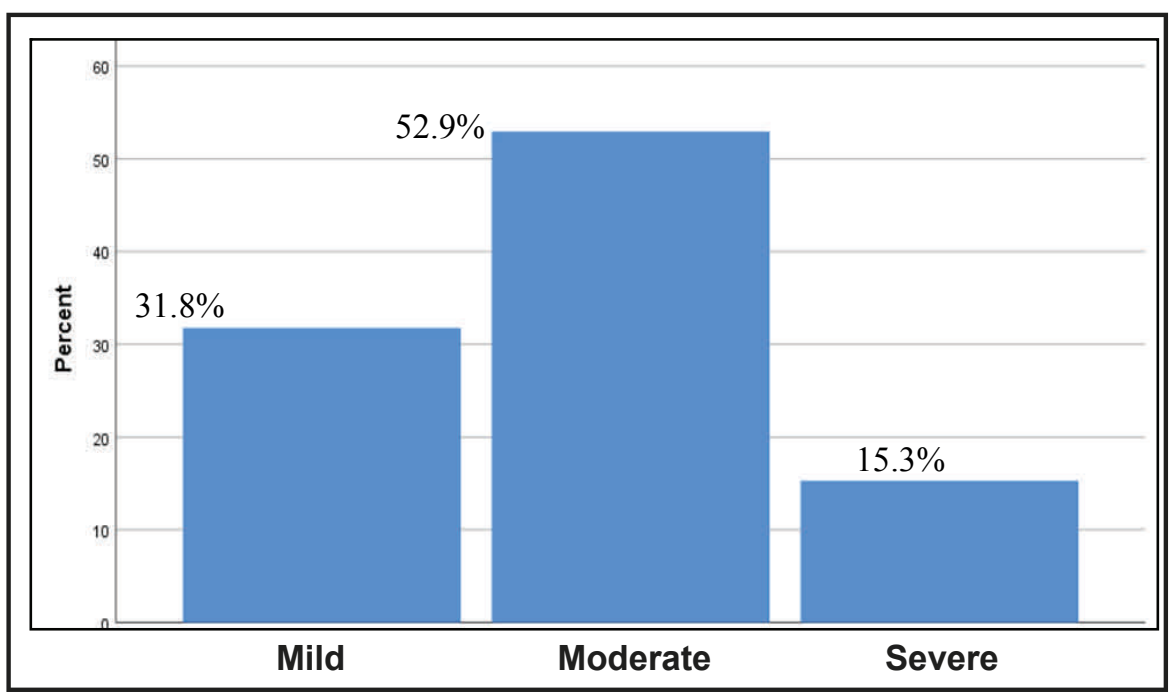

Figure 1: Prevalence of severity of major depressive disorder in patients with multiple sclerosis in Erbil city. 


\section{Discussion}

Studies have shown that major depression had an impact on chronic illnesses, negatively affects functioning and compliance with medications. Treatment of depression will reduce additional disability in patients with multiple sclerosis. ${ }^{21}$ The importance of our study is that depression may affect the response of patients with multiple sclerosis to treatment. Newly diagnosed patients with multiple sclerosis may benefit from early psychological intervention. $^{22}$ Depression in multiple sclerosis like other chronic illnesses will affect the quality of life, adherence to medication, and disability progression. ${ }^{23}$ An evidence newly emerged for the relationship between depression and disruption of the immune system, and there is a bidirectional relationship. ${ }^{24}$ Additionally, untreated depression in multiple sclerosis may increase the risk of suicide. ${ }^{25}$ The results of the present study reveal a high prevalence of depression among patients with multiple sclerosis in Erbil city, which is about $53.5 \%$; this is close to several previous studies that shown to be around $50 \% .{ }^{11}$ Depending on the diagnostic criteria and sample size that had been used, the prevalence of depression ranges from 19 to $54 \% .^{19}$ In one study done in Sultan Qaboos University Hospital in Oman, the prevalence of depression in patients with MS was about $51 \% .{ }^{26}$ In one case control study from Iraq that involved 50 patients with multiple sclerosis compared with another 51 healthy controls matched in age and sex, the prevalence of major depressive disorder was $44 \%$ compared to control $2.0 \% .{ }^{27}$ In another study conducted in Canada for those in the $18-45$ year age range, the prevalence of major depression was $25.7 \%$ with multiple sclerosis. ${ }^{28}$ This difference may be due to sample size, type of the study, scales had been used, and many other factors. Most probably, there are many factors that contributed to revealing this high prevalence of depression in patients with multiple sclerosis in Erbil city, which may be superadded to the effect of multiple sclerosis; economic and political crises in our country. However; somatic complaints such as fatigue and cognitive complaints in persons with multiple sclerosis that may be difficult to be distinguished from depressive symptoms might over represent the level of depression. ${ }^{29}$ Our study shows a significant increase in depression in age group more than 50 years in patients with multiple sclerosis as shown in Table 1. This may be related to a decrease in physical activity or thinking process that is affected by social and environmental dealing. There is no clear association between depression and older age group in patients with multiple sclerosis. ${ }^{30}$ The long duration of multiple sclerosis has an impact on healthcare systems and the individual patient. ${ }^{31}$ This may be the cause behind the significant result of our research about the relationship between depression and a long duration of more than 10 years of multiple sclerosis. Furthermore, reduction in quality of life, costs of individual, family, and work productivity resulted from a long duration of multiple sclerosis. ${ }^{32}$ Within 10 years of multiple sclerosis diagnosis, half to three-quarters are unemployed. ${ }^{33}$ All of these may increase the risk of depression in long-standing multiple sclerosis. Interferon beta 1-a and 1-b, glatiramer acetate, mitoxantrone, natalizumab, fingolimod, teriflunomide, dimethyl fumarate, and alemtuzumab are Disease-modifying therapies for multiple sclerosis approved by the European Medicine Agency and Food and Drug Administration. Also, methotrexate and rituximab are used as an off-label option in some cases. ${ }^{34}$ There was a significant increase in depression in patients who used rituximab in their management for multiple sclerosis in the present study, as shown in Table 2. For autoimmune disease, rituximab is used increasingly as an off-label drug in many cases. ${ }^{35}$ For multiple sclerosis, it is still investigational agent. ${ }^{36}$ In contrast to the present study, in some reports it had been recorded that rituximab 
may decrease the prevalence of depression37 and showed to be effective in some cases of chronic fatigue syndrome that characterized by severe fatigue, headache, and cognitive disturbance.38 However, other studies showed a high prevalence of fatigue and headache in patients using rituximab, ${ }^{39}$ and symptoms that may misdiagnosed with symptoms of depression. There is no clear relation between depression and the use of rituximab in multiple sclerosis, which need further studying. Interferons (IFNs) are used for the treatment of autoimmune disorders, including MS, because of the immunomodulatory properties. The neuropsychiatric adverse effects of IFNs include depression, irritability, anxiety, and agitation. Attributing all these changes exclusively to IFN treatment can be difficult because the conditions for which IFNs are prescribed are often themselves associated with neuropsychiatric symptom. ${ }^{17}$ In contrast to many studies that show the effect of beta interferon in depression, ${ }^{40}$ our study does not bring to light this effect.

\section{Conclusion}

The high prevalence rate of depression among patients with multiple sclerosis may have a negative impact on treatment adherence, quality of life, and disability progression. This may be related to the depressive symptoms and effect in addition to the inflammatory process of the disease itself or personal or environmental factors. Medication used in multiple sclerosis may have a role that needs further studies.

\section{Competing interests}

The authors declare no competing interests.

\section{References}

1. Kingwell E, Marriott JJ, Jetté N, Pringsheim T, Makhani N, Morrow SA, et al. Incidence and prevalence of multiple sclerosis in Europe: a systematic review. BMC Neurol 2013; 13:128.

2. Newland $P$, Starkweather A, Sorenson M. Central fatigue in multiple sclerosis: a review of the literature. J Spinal Cord Med 2016; 39(4):38699.
3. Alonso A, Hernán MA. Temporal trends in the incidence of multiple sclerosis: a systematic review. Neurology 2008; 71(2):129-35.

4. Vargas GA, Arnett PA. Attributional style and depression in multiple sclerosis: the learned helplessness model. Int J MS Care 2013; 15(2):81-9.

5. Goldenberg MM. Multiple sclerosis review. P T 2012; 37(3):175-84.

6. Loma I, Heyman R. Multiple sclerosis: pathogenesis and treatment. Curr Neuropharmacol 2011; 9(3):409-16.

7. Schippling S, O'Connor P, Knappertz V, Pohl C, Bogumil T, Suarez G, et al. Incidence and course of depression in multiple sclerosis in the multinational BEYOND trial. J Neurol 2016; 263(7):1418-26.

8. Marrie RA, Fisk JD, Tremlett $H$, Wolfson C, Warren S, Tennakoon A, et al. Differences in the burden of psychiatric comorbidity in MS vs the general population. Neurology 2015; 85(22):1972 -9 .

9. Marrie RA, Reingold S, Cohen J,Stuve O, Trojano M, Sorensen PS, et al. The incidence and prevalence of psychiatric disorders in multiple sclerosis: a systematic review. Mult Scler 2015; 21(3):305-17.

10. Skokou M, Soubasi E, Gourzis P. Depression in multiple sclerosis: a review of assessment and treatment approaches in adult and pediatric populations. ISRN Neurol 2012; 2012:427102.

11. Siegert RJ, Abernethy DA. Depression in multiple sclerosis: a review. J Neurol Neurosurg Psychiatry 2005; 76(4):469-75.

12. Beal CC, Stuifbergen AK, Brown A. Depression in multiple sclerosis: a longitudinal analysis. Arch Psychiatr Nurs 2007; 21(4):181-91.

13. Brigitta B. Pathophysiology of depression and mechanisms of treatment. Dialogues Clin Neurosci 2002; 4(1):7-20.

14. Joffe RT. Depression and multiple sclerosis: a potential way to understand the biology of major depressive illness. J Psychiatry Neurosci 2005; 30(1):9-10.

15. Pucak ML, Carroll KA, Kerr DA, Kaplin AI. Neuropsychiatric manifestations of depression in multiple sclerosis: neuroinflammatory, neuroendocrine, and neurotrophic mechanisms in the pathogenesis of immune-mediated depression. Dialogues Clin Neurosci 2007; 9(2):125-39.

16. Johansson S, Gottberg K, Kierkegaard $M$, Ytterberg C. Variations in and predictors of the occurrence of depressive symptoms and mood symptoms in multiple sclerosis: a longitudinal two-year study. BMC Neurol 2016; 16:32.

17. Pinto EF, Andrade C. Interferon-Related Depression: A Primer on Mechanisms, Treatment, and Prevention of a Common Clinical Problem. Curr Neuropharmacol 2016; 14(7):7438. 
18. Raosoft. Sample Size Calculator 2016. (Accessed November 7, 2016, available at: http://www.raosoft.com/samplesize.html).

19. Skokou M, Soubasi E, Gourzis P. Depression in Multiple Sclerosis: A Review of Assessment and Treatment Approaches in Adult and Pediatric Populations. ISRN Neurol 2012; 2012:427102.

20. Lee EH, Lee SJ, Hwang ST, Hong SH, Kim JH. Reliability and Validity of the Beck Depression Inventory-II among Korean Adolescents. Psychiatry Investig 2016; 14(1):30-6.

21. Chwastiak L, Ehde DM, Gibbons LE, Sullivan M, Bowen JD, Kraft GH. Depressive symptoms and severity of illness in multiple sclerosis: epidemiologic study of a large community sample. Am J Psychiatry 2002; 159(11):1862-8.

22. Greenberg B, Fan Y, Carriere L, Sullivan A. Depression and Age at First Neurology Appointment Associated with Receipt of Behavioral Medicine Services Within 1 Year in a Multiple Sclerosis Population. Int J MS Care 2017; 19(4):199-207.

23. Moore S. Major depression and multiple sclerosis - a case report. J Med Life 2013; 6(3):290-1.

24. Voinov B, Richie WD, Bailey RK. Depression and chronic diseases: it is time for a synergistic mental health and primary care approach. Prim Care Companion CNS Disord 2013; 15(2):PCC.12r01468.

25. Bhattacharjee S, Goldstone L, Ip Q, Warholak T. Depression Treatment among Adults with Multiple Sclerosis and Depression in Ambulatory Care Settings in the United States. Mult Sclerlnt 2017; 2017:3175358.

26. Al-Asmi A, Al-Rawahi S, Al-Moqbali ZS, Al-Farsi $Y$, Essa MM, El-Bouri M, et al. Magnitude and concurrence of anxiety and depression among attendees with multiple sclerosis at a tertiary care Hospital in Oman. BMC Neurol 2015; 15:131.

27. Gorial FI, Swady RN. Prevalence of Depression in Iraqi Patients with Systemic Sclerosis and Its Relationship with Disease Severity. International Journal of Medical Research \& Health Sciences 2018; 7(4):69-74.

28. Patten SB, Beck CA, Williams JV, Barbui C, Metz LM. Major depression in multiple sclerosis: a population-based perspective. Neurology 2003; 61(11):1524-7.

29. Braley TJ, Chervin RD. Fatigue in Multiple Sclerosis: Mechanisms, Evaluation, and Treatment. Sleep 2010; 33(8):1061-7.

30. Jones SM, Amtmann D. The relationship of age, function, and psychological distress in multiple sclerosis. Psychol Health Med 2014; 20(6):629_ 34.

31. Gold R, Wolinsky JS, Amato MP, Comi G. Evolving expectations around early management of multiple sclerosis. Ther Adv Neurol Disord 2010; 3(6):351-67.

32. Chwastiak LA, Ehde DM. Psychiatric issues in multiple sclerosis. Psychiatr Clin North Am 2007;
30(4):803-17.

33. Rahn K, Slusher B, Kaplin A. Cognitive impairment in multiple sclerosis: a forgotten disability remembered. Cerebrum 2012; 2012:14.

34. Gajofatto A, Benedetti MD. Treatment strategies for multiple sclerosis: When to start, when to change, when to stop? World J Clin Cases 2015; 3(7):545-55.

35. Randall KL. Rituximab in autoimmune diseases. AustPrescr 2016; 39(4):131-4.

36. Loma I, Heyman R. Multiple sclerosis: pathogenesis and treatment. Curr Neuropharmacol 2011; 9(3):409-16.

37. Kwiatkowska B, Kłak A, Maślińska M, Mańczak M, Raciborski F. Factors of depression among patients with rheumatoid arthritis. Reumatologia 2018; 56(4):219-27.

38. Fluge $\varnothing$, Mella $\bigcirc$. Clinical impact of B-cell depletion with the anti-CD20 antibody rituximab in chronic fatigue syndrome: a preliminary case series. BMC Neurol 2009; 9:28.

39. Xie Q, Li X, Sun J, Yuan B, Li Y, Wang L, et al. A meta-analysis to determine the efficacy and tolerability of anti-B-cell monoclonal antibodies in multiple sclerosis. Exp Ther Med 2017; 13(6):3061-6.

40. Lana-Peixoto MA, Teixeira AL, Haase VG. Interferon beta-1a-induced depression and suicidal ideation in multiple sclerosis. Arq Neuropsiquiatr 2002; 60(3-B):721-4. 